\title{
Effect of Urbanization on Climate Change in Nanjing
}

\author{
QI YingXiang ${ }^{1}$, Yu Wenzheng ${ }^{1,2}$, Shao $\mathrm{Li}^{2}$ and Chen Tianliang ${ }^{2}$ \\ ${ }^{1}$ School of Public Administration Nanjing University of Information Science \& \\ Technology, Jiangsu Nanjing, 210044, China \\ ${ }^{2}$ College of Environmental Science and Engineering, Nanjing University of \\ Information Science \& Technology, Jiangsu Nanjing, 210044, China
}

\begin{abstract}
This paper chose urbanization and climate change of Nanjing city as the research object, by using trend analysis, correlation analysis, multivariate linear regression analysis and other methods, using the climate data and social statistical data of 1951 2011 observation stations in Nanjing City, analyzing the trend of cityclimate change and the correlation between different parameters and mainclimate factors. Results show that, the warming trend in Nanjing is very weak, the mainly temperature change is a rising temperature in winter, while it was rot obvious in summer, reduce the heat wave phenomenon, the average year temperature has increased slightly; over the years precipitation showed increasing trend, the sunlight hours was decreasing, in addition to the city dark island effect. Through the analysis-of the relationships between urbanization and climatic factors found that close relations between urbanization and annual mean temperature, and its impact is significant, and the impact of extreme minimum temperature is not very obvious, but the but the influence of extreme maximum temperature is obvious. In addition in the analysts of Nanjing found that years of reform and opening up has become theohes of demarcation point climate change trends and impacts of urbanization on climate change, before and after the cut-off point on climate change and the effects of urbanization on climate change have has the remarkable differences, the reason andmechanism still need further analysis and discussion.
\end{abstract}

Keywords: Nanjing City, urbanization, climate change

\section{Introdaction}

Urbanization is the agricultural population shift to non-agricultural population, industrial structure from primary industry to secondary industry and service sector, it is caused by human activity, extreme of anthropogenic land use change (Jin Menglin et al., 2005)[1]. The 2011 Annual Report of the UN Human Settlements Programme "cities and climate change" pointed out that urbanization and climate change are intertwined in a dangerous way [2]. On one hand, with the rapid development of urbanization, urban greemouse gas emissions from the consumption and production has accounted for $70 \%$ of in total amount of greenhouse gases, the city became the world's largest source of greenhouse gases; On the other hand, climate change for urban development and its ever-growing population poses unique challenges, its influence spread to urban water supply, infrastructure, transportation, ecosystems, energy supply, industrial production, the livelihood of the residents of the city and many other aspects. In the context of climate warming, urbanization and local climate change caused by human activities and the city environmental quality problems, has been widespread concern, the scope of its influence is growing, domestic and foreign scholars and experts also put considerable effort in research and discussion in this regard. It is necessary to explore the urbanization climate effect peculiar to the city, either to improve urban habitat comfort index, or for the future of the city sustainable development is of great significance. 
Nanjing is located in the middle of the lower reaches of the Yangtze River, the east of China, a national and regional center city in china at $118^{\circ} 22^{\prime} \sim 119^{\circ} 14^{\prime} \mathrm{E}, 31^{\circ} 14^{\prime} \sim 32^{\circ} 37^{\prime} \mathrm{N}$, belongs to the northern subtropics monsoon climate zone, four seasons, mild climate, moderate rainfall. In recent years, urbanization has been developing rapidly in Nanjing, the population surged from 1.56 million in the period of reform and opening up to 8 million in 2011. And In economic terms, the GDP of Nanjing developed from 17.7 billion RMB in the 90s last century to 614.6 billion RMB in 2011, got great development of urban economy. But at the same time, climate change and environmental quality of Nanjing urbanization cause for worry.

\section{Research Materials and Methods}

The climate data of observation stations in Nanjing during 1951 2011 is used in this article. Select extreme maximum temperature and extreme minimum temperature, average, temperature, annual precipitation and sunshine time in each year as analysis object. The data of economic index from the Nanjing Statistical Bureau in 1951 2011 selection of related parameters of population, GDP, and municipal construction as the research object. Research methods mainly use the trend analysis, correlation analysis and mulíple linear regression analysis, etc.

\section{Climate Change of Nanjing in Recent Decades}

\subsection{The Tendency of Temperature in Nanjing in Recent 6 Years}

Nanjing has long been known as "stove thanks to the high-temperature heat wave in summer. Use 1951-2009 (June-September)-meteorological data, examined the characteristics of high-temperature heat wave in Nanjing eity (Xu Xiazhen et al., 2011) [3]. Results show that Nanjing is the city of various level of heat and frequent heat wave. In the past 60 years, the number of high average temperature days in Sanjing is $14.5 \mathrm{~d}$, the number of harmful high temperature days is $1.1 \mathrm{~d}$, occurred heat wave 1.9 times and strong heat wave 0.8 times in annual average. And, among 2005 to 2008 , high temperature heat wave came 8 times in totally. Trend analysis method is used to discuss the change of extreme high temperature, extreme minimum temperature, average temperature in 1951-2011. The result is shown in Figure 1 and Figure 2. As can be seen from the Figure 1, over the past 60 years, the years of highest temperature in Nanjing were mainly in the sixties and seventies of the 20th century and the early 21 st century. Although in recent years, Nanjing's highest temperature dropped slightly, but still kept above $35 \mathrm{C}$, The minimum temperature rose to $-10{ }^{\circ} \mathrm{C}$ or higher, shown a tendency of warming. As can be seen from the Figure 2, the tendency of warming is weak, the highest temperatufe was $17.4^{\circ} \mathrm{C}$ in 2007 , but in recent years also has a tendency to fall, dropped by $1.3^{\circ} \mathrm{C}$ to 2011 .

Judging from the comprehensive analysis of Figure 1 and Figure 2, in the context of global warming, The temperature in Nanjing in the past 60 years rose very weak, the temperature change was mainly seem a rising temperature in winter and it was not very obvious in summer, but the heat wave phenomenon became less, the year average temperature had increased slighly. 

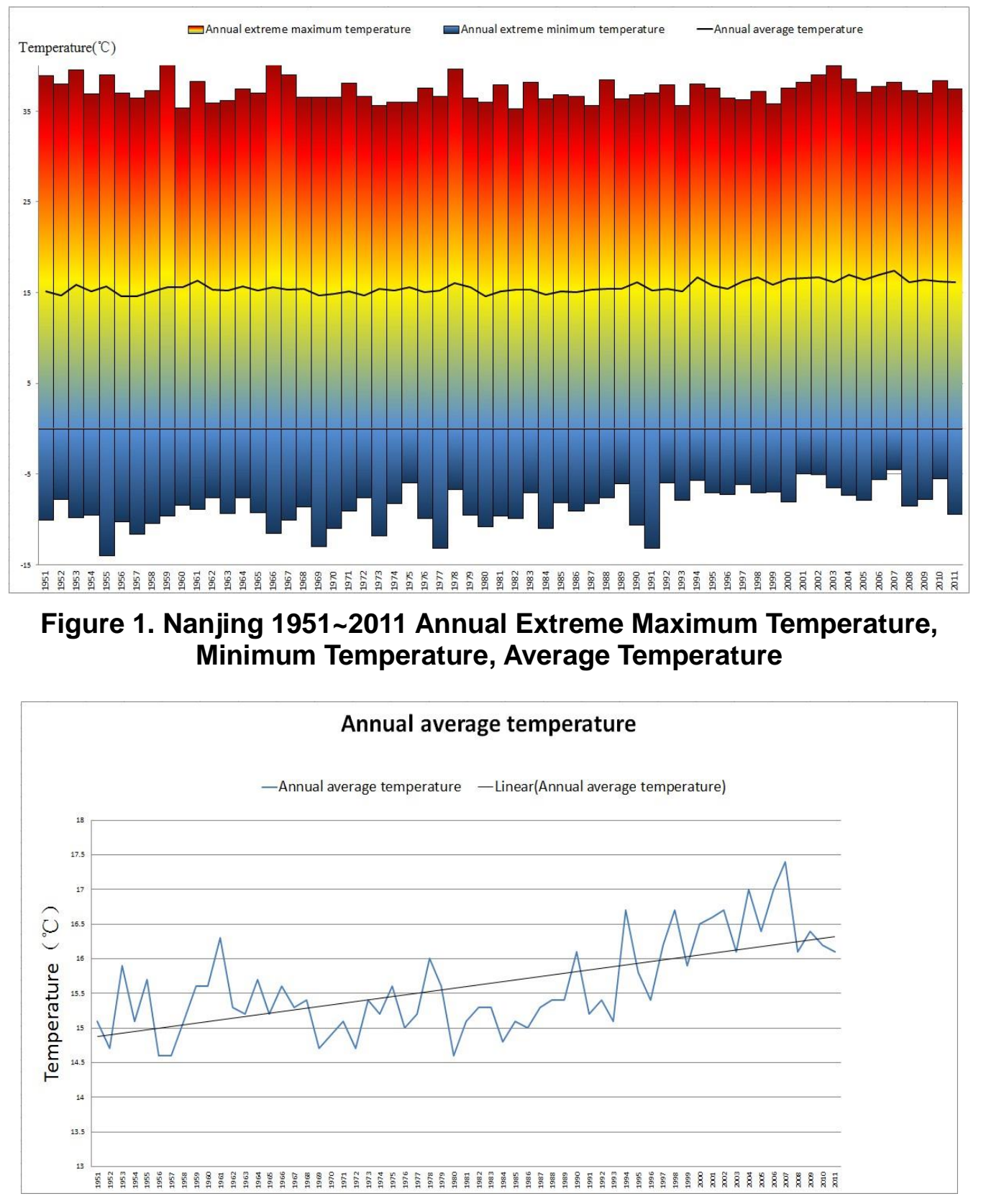

Figure 2, The Change for the Trend of Nanjing 1951 2011annual Average

\subsection{The Change of Precipitation and Sunlight Hours in Nanjing}

Trend analysis method is used to analyze the change of precipitation and sunlight hours, results are shown in Figure 3. It shows an increasing trend of precipitation in recent decades in Nanjing, precipitation increase $17.43 \mathrm{~mm}$ every 10 years. Precipitation reached the maximum in 1991, to $1825.8 \mathrm{~mm}$, while the minimum precipitation year appeared in 1978 , to $534.0 \mathrm{~mm}$. We take 1978 as a division point, before 1978 , the trend of precipitation changed for $-9.11 \mathrm{~mm} / 10 \mathrm{a}$, and after 1978 , it was changed for $36.17 \mathrm{~mm} / 10 \mathrm{a}$, and 1978 was the year of the reform and opening up in China, so the conclusion needs further research and analysis, if the change of precipitation is related to development of urbanization after reform and opening up.

Inter-annual variability of sunlight hours in Nanjing is decreasing, as we can see in Figure 3, sunlight hours decreased 66.28h every 10 years. We take 1978 as a division 
point, before 1978, the trend of sunlight hours changed for $-43.88 \mathrm{~h} / 10 \mathrm{a}$, and after 1978 , it was changed for $-17.13 \mathrm{~h} / 10 \mathrm{a}$, since the reform and opening up, the sunlight hours reduced more slowly, this situation may be related to the progress of society and the human awareness of environmental protection, but the exact reason needs further study. But overall, the number of sunlight hours in Nanjing continues decreasing, reflecting the effect of city dark island, which may be caused by the process of urbanization and other environmental pollution that are inseparable.

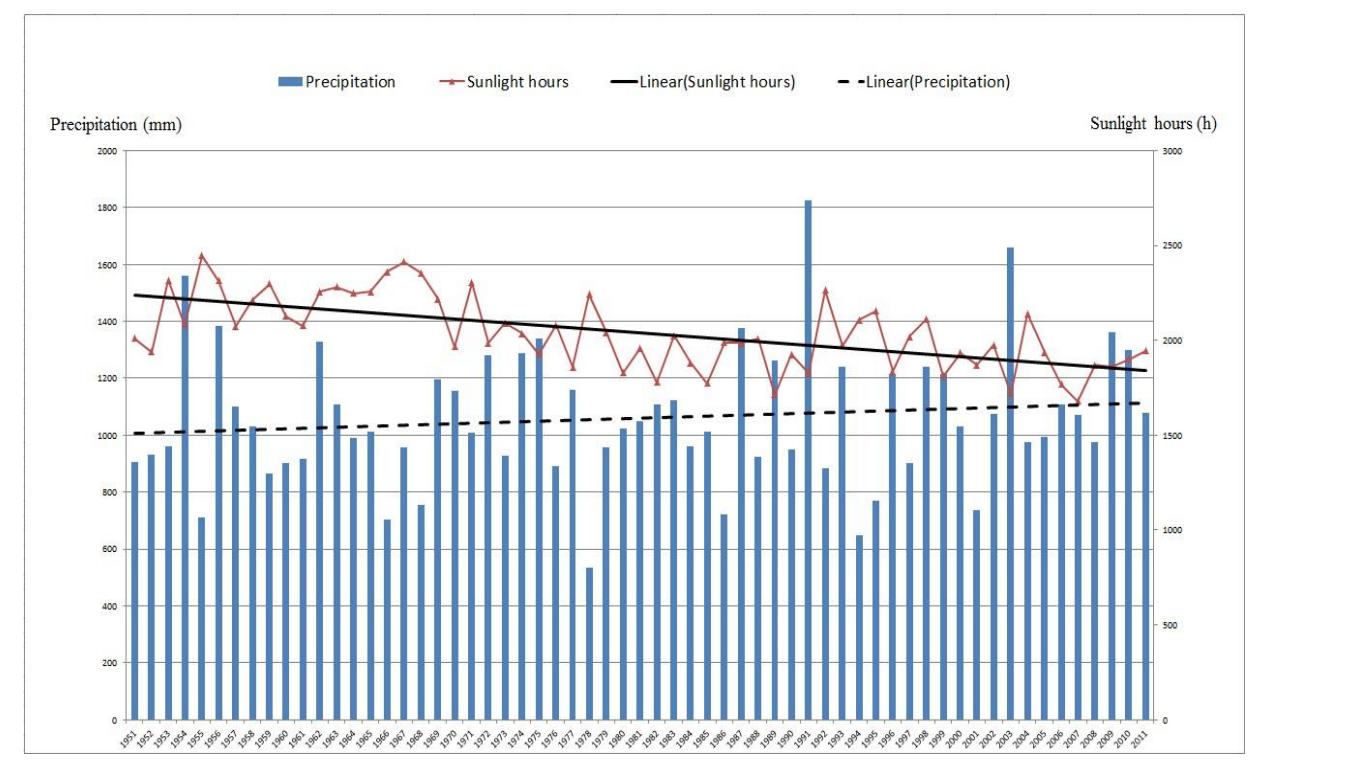

Figure 3. The Interannual Change and Linear Trend of Nanjing Precipitation and Sunlight Hours in Recent Years

\section{Effects of Urbanization on Climate Change in Nanjing}

\subsection{Data Preprocessing}

Through visiting, investigation, refence the existing research results, we choose GDP $\left(\mathrm{X}_{1}\right)$ ( one hyndred million $\mathrm{RMB}$ ), the first industry $\left(\mathrm{X}_{2}\right)$ ( one hundred million $\mathrm{RMB}$ ), the second industry $\left(\mathrm{X}_{3}\right)$ ( one huhdred million $\mathrm{RMB}$ ), industrial $\left(\mathrm{X}_{4}\right)$ ( one hundred million $\mathrm{RMB}$ ), the tertiary industry $\left(\mathrm{X}_{5}\right)$ ( one hundred million RMB), per capita GDP $\left(\mathrm{X}_{6}\right)$ ( one hundred million $\mathrm{RMB}$, total population $\left(\mathrm{X}_{7}\right)$ ( million people), non-agricultural population $\left(\mathrm{X}_{8}\right)$ ( million people), the agricultural population $\left(\mathrm{X}_{9}\right)$ (million people), road length $\left(\mathrm{X}_{10}\right)(\mathrm{km})$, road area $\left(\mathrm{X}_{11}\right)\left(\right.$ Million square meters), green coverage area $\left(\mathrm{X}_{12}\right)$ ( hectare), land area $\left(X_{13}\right)$ ( Thousands of hectares), the whole society passenger traffic $\left(X_{14}\right)$ and the urban consumer price index $\left(\mathrm{X}_{15}\right)$ as the target of urbanization. And select the annual average temperature $\left(\mathrm{Y}_{1}\right)\left(0.1^{\circ} \mathrm{C}\right)$, extreme minimum temperature $\left(\mathrm{Y}_{2}\right)\left(0.1^{\circ} \mathrm{C}\right)$, extreme maximum temperature $\left(\mathrm{Y}_{3}\right)\left(0.1^{\circ} \mathrm{C}\right)$, precipitation $\left(\mathrm{Y}_{4}\right)(0.1 \mathrm{~mm})$ and sunshine hours $\left(\mathrm{Y}_{5}\right)(0.1 \mathrm{~h})$ as the meteorological factors to reflect climate change.

Due to the unit and the value range of each independent variable is different, In order to calculate under the influence of non-dimensional, in this paper, using the standard method of standard deviation (Z-score standard) to remove the influence of different dimensions on regression model (Table1). 
Table 1. Standardized Data of each Index

\begin{tabular}{|c|c|c|c|c|c|c|c|c|c|c|}
\hline Year & $\mathrm{X}_{1}$ & $\mathrm{X}_{2}$ & $\mathrm{X}_{3}$ & $\mathrm{X}_{4}$ & $\mathrm{X}_{5}$ & $\mathrm{X}_{6}$ & $\mathrm{X}_{7}$ & $\mathrm{X}_{8}$ & $\mathrm{X}_{9}$ & $\mathrm{X}_{10}$ \\
\hline 1978 & -0.7370 & -0.9974 & -0.7511 & -0.7540 & -0.7088 & -0.7747 & -1.7513 & -1.2641 & 0.5921 & -0.7407 \\
\hline 1979 & -0.7340 & -0.9835 & -0.7472 & -0.7511 & -0.7071 & -0.7713 & -1.4886 & -1.0854 & 0.5264 & -0.7345 \\
\hline 1980 & -0.7320 & -0.9756 & -0.7443 & -0.7460 & -0.7061 & -0.8047 & -1.3859 & -1.0294 & 0.5295 & -0.7364 \\
\hline 1981 & -0.7312 & -0.9654 & -0.7439 & -0.7461 & -0.7056 & -0.7688 & -1.2700 & -0.9851 & 0.5720 & -0.7464 \\
\hline 1982 & -0.7285 & -0.9412 & -0.7398 & -0.7436 & -0.7054 & -0.7657 & -1.1581 & -0.9402 & 0.5004 & -0.7321 \\
\hline 1983 & -0.7266 & -0.9293 & -0.7350 & -0.7386 & -0.7064 & -0.7636 & -1.0679 & -0.8964 & 0.6213 & -0.7297 \\
\hline 1984 & -0.7179 & -0.8961 & -0.7260 & -0.7293 & -0.6993 & -0.7520 & -0.9988 & -0.7222 & 0.3417 & -0.7254 \\
\hline 1985 & -0.7087 & -0.8545 & -0.7162 & -0.7165 & -0.6923 & -0.7401 & -0.9207 & -0.6519 & 0.2865 & -0.7183 \\
\hline 1986 & -0.6989 & -0.7992 & -0.7073 & -0.7076 & -0.6842 & -0.7278 & -0.8298 & -0.7714 & 0.6395 & -0.7021 \\
\hline 1987 & -0.6861 & -0.7830 & -0.6938 & -0.6959 & -0.6722 & -0.7119 & -0.7029 & -0.7183 & 0.6767 & -0.6897 \\
\hline 1988 & -0.6698 & -0.7458 & -0.6741 & -0.6759 & -0.6601 & -0.6924 & -0.5711 & -0.6486 & 0.6852 & -0.9823 \\
\hline 1989 & -0.6634 & -0.7140 & -0.6663 & -0.6611 & -0.6564 & -0.6862 & -0.4482 & -0.5988 & 0.7243 & -0.9470 \\
\hline 1990 & -0.6483 & -0.6965 & -0.6522 & -0.6456 & -0.6405 & -0.6687 & -0.3598 & -0.5690 & 0.7651 & -0.7140 \\
\hline 1991 & -0.6322 & -0.6819 & -0.6369 & -0.6305 & -0.6236 & -0.6500 & -0.2880 & -0.5425 & 0.7936 & -0.7016 \\
\hline 1992 & -0.5939 & -0.6343 & -0.5897 & -0.5805 & -0.5939 & -0.6038 & -0.2318 & -0.5100 & 0.7912 & -0.6964 \\
\hline 1993 & -0.5367 & -0.5102 & -0.5224 & -0.5112 & -0.5494 & -0.5351 & -0.1588 & -0.4586 & 0.7694 & -0.6883 \\
\hline 1994 & -0.4638 & -0.2879 & -0.4456 & -0.4247 & -0.4879 & -0.4482 & -0.1037 & -0.4159 & 0.7447 & -0.6806 \\
\hline 1995 & -0.3936 & -0.0527 & -0.3788 & -0.3769 & -0.4235 & -0.3656 & -0.0502 & -0.3703 & 0.7124 & \\
\hline 1996 & -0.3323 & -0.0304 & -0.3218 & -0.3333 & -0.3565 & -0.2948 & 0.0075 & -0.3197 & 0.6745 & \\
\hline 1997 & -0.2755 & 0.0606 & -0.2670 & -0.2752 & -0.2999 & -0.2309 & 0.0758 & -0.2740 & 0.6588 & 0.4700 \\
\hline 1998 & -0.2278 & 0.1041 & -0.2312 & -0.2457 & -0.2414 & -0.1780 & 0.1145 & -0.2207 & 0.5933 & -0.4224 \\
\hline 1999 & -0.1731 & 0.1461 & -0.1950 & -0.2040 & -0.1696 & -0.1179 & 0.1943 & -0.1267 & & -0.3804 \\
\hline 2000 & -0.0884 & 0.2398 & -0.1149 & -0.1154 & -0.0816 & -0.0273 & 00 & $>0.0691$ & 02197 & -0.3218 \\
\hline 2001 & 0.0021 & 0.3415 & -0.0433 & -0.0449 & 0.0249 & 0.0655 & & 0.1940 & 0.1080 & 0.6843 \\
\hline 2002 & 0.1061 & 0.4296 & 0.0463 & 0.0389 & 0.1423 & 0.1685 & & 0.3288 & 0.0133 & 1.3777 \\
\hline 2003 & 0.2969 & 0.5174 & 0.3064 & 0.3044 & 0.2760 & 0.3639 & 0.7356 & 0.784 & 0.7691 & 1.4410 \\
\hline 2004 & 0.5318 & 0.6513 & 0.5802 & 0.5833 & 0.4808 & 0.5996 & 0.9125 & & -1.0460 & 1.5590 \\
\hline 2005 & 0.7465 & 0.7621 & 0.8466 & 0.8562 & 0.6541 & 8009 & 1.1023 & & -1.1310 & 1.7414 \\
\hline 2006 & 0.9729 & 0.8081 & 1.0634 & 1.0743 & 0.8979 & 1.0065 & 1.2801 & 4785 & -1.5762 & 1.3183 \\
\hline 2007 & 1.2912 & 0.9108 & 1.3990 & 1.4361 & 1.2110 & 1.2972 & 1.4348 & 1.5650 & -1.5761 & 1.3321 \\
\hline 2008 & 1.6225 & 1.6766 & 1.6217 & 1.6246 & & 1.6098 & & 1.8773 & -2.0919 & 1.3726 \\
\hline 2009 & 1.8820 & 1.9038 & 1.8380 & 1.7948 & & 1.8463 & 1.6308 & 1.6855 & -1.5986 & 1.4247 \\
\hline 2010 & 2.3703 & 2.2082 & 2.3772 & 2.3679 & & 2.3174 & 1.6720 & 1.8196 & -1.8286 & 1.4875 \\
\hline 2011 & 3.0775 & 2.7191 & 2.9649 & 2.9733 & 3. 880 & & 1.7333 & 2.1359 & -2.4130 & 1.6261 \\
\hline Year & $\mathrm{X}_{11}$ & $\mathrm{X}_{12}$ & $\mathrm{X}_{13}$ & $\mathrm{X} / 4$ & $\mathrm{X}_{15}$ & & $\mathrm{Y}_{2}$ & $\mathrm{Y}_{3}$ & $\mathrm{Y}_{4}$ & $\mathrm{Y}_{5}$ \\
\hline 1978 & -0.7748 & -0.7197 & -0.4688 & 0.8745 & 0.4147 & 0.1701 & 0.5066 & 2.0814 & -2.0523 & 2.0937 \\
\hline 1979 & -0.7588 & -0.7537 & -0.5177 & -0.8483 & -0.7320 & -0.3942 & -0.9160 & -0.7423 & -0.4263 & 0.7160 \\
\hline 1980 & -0.7498 & -0.7534 & -0.5462 & -0.8163 & & -1.8052 & -1.5765 & -1.1835 & -0.1718 & -0.7412 \\
\hline 1981 & -0.7537 & -0.7534 & -0.5616 & -0.7853 & -0.6895 & -1.0997 & -0.9668 & 0.4931 & -0.0687 & 0.1404 \\
\hline 1982 & -0.7480 & -0.7532 & -0.5781 & -0.7613 & -0.6329 & -0.8175 & -1.1192 & -1.8011 & 0.1489 & -1.0849 \\
\hline 1983 & -0.7404 & & 0.5977 & & -0.7036 & -0.8175 & 0.3541 & 0.7578 & 0.2162 & 0.5939 \\
\hline 1984 & -0.7307 & & -0.6480 & -0.7083 & -0.1516 & -1.5230 & -1.6781 & -0.8305 & -0.4148 & -0.3769 \\
\hline 1985 & -0.7301 & & & & 0.5421 & -1.0997 & -0.2047 & -0.4775 & -0.2094 & -1.1137 \\
\hline 1986 & -0.7262 & 0.6520 & -0.6840 & -0.6786 & -0.0100 & -1.2408 & -0.6620 & -0.5658 & -1.3275 & 0.3565 \\
\hline 1987 & & -0.6386 & -0.6957 & -0.6536 & 0.7686 & -0.8175 & -0.2555 & -1.4482 & 1.1924 & 0.3401 \\
\hline 1988 & -0.8268 & -0.6380 & -07148 & -0.6431 & 2.1842 & -0.6764 & 0.0493 & 1.0225 & -0.5493 & 0.4924 \\
\hline 1989 & -0.8084 & -0.6362 & -0.7329 & -0.6767 & 1.4339 & -0.6764 & 0.8622 & -0.8305 & 0.7441 & -1.5336 \\
\hline 1990 & -0.6613 & & 0.7426 & -0.7047 & -0.1374 & 0.3112 & -1.4748 & -0.4775 & -0.4513 & -0.0798 \\
\hline 1991 & -0.6568 & & -0.7595 & -0.7114 & 0.5421 & -0.9586 & -2.7450 & -0.3011 & 2.9145 & -0.7680 \\
\hline 1992 & -0.6438 & & -0.7929 & -0.7023 & 0.5846 & -0.6764 & 0.9130 & 0.4931 & -0.7020 & 2.2549 \\
\hline 1993 & -0.6314 & -0.6145 & -0.8305 & -0.7250 & 2.0285 & -1.0997 & -0.1031 & -1.4482 & 0.6679 & 0.2385 \\
\hline 1994 & -0.6187 & -0.6135 & -0.8955 & -0.7250 & 2.8637 & 1.1578 & 1.0146 & 0.5813 & -1.6143 & 1.1627 \\
\hline 1995 & -0.5620 & -0.6099 & -0.9199 & -0.2641 & 1.2499 & -0.1120 & 0.3541 & 0.2284 & -1.1422 & 1.4975 \\
\hline 1996 & -0.5049 & -0.6051 & -0.9552 & -0.1811 & 0.5704 & -0.6764 & 0.2525 & -0.7423 & 0.5603 & -0.6795 \\
\hline 1997 & 0.4357 & -0.6038 & 1.4115 & -0.0239 & -0.9301 & 0.4523 & 0.8114 & -0.9187 & -0.6343 & 0.5713 \\
\hline & -0.3769 & -0.5996 & 1.3473 & 0.0351 & -0.8877 & 1.1578 & 0.3541 & -0.1246 & 0.6583 & 1.2004 \\
\hline 1999 & -0.3264 & -0.5743 & 2.6384 & 0.0700 & -1.0859 & 0.0290 & 0.4049 & -1.3599 & 0.5641 & -0.8517 \\
\hline 2000 & -0.2875 & -0.5691 & 2.4860 & 0.1566 & -0.8877 & 0.8756 & -0.1539 & 0.2284 & -0.1468 & -0.0270 \\
\hline 2001 & 0.4320 & 0.2350 & 2.1863 & 0.2293 & -0.9018 & 1.0167 & 1.4210 & 0.7578 & -1.2706 & -0.4558 \\
\hline 2002 & 0.6933 & 1.2392 & 0.9376 & 0.2833 & -1.1850 & 1.1578 & 1.3702 & 1.4637 & 0.0262 & 0.2673 \\
\hline 2003 & 0.8464 & 1.2600 & 0.5207 & 0.2779 & -0.6895 & 0.3112 & 0.6082 & 2.3461 & 2.2705 & -1.4966 \\
\hline 2004 & 1.0225 & 1.3330 & 0.3356 & 0.4867 & -0.4630 & 1.5811 & 0.2017 & 1.1108 & -0.3563 & 1.4000 \\
\hline 2005 & 1.2953 & 1.3877 & 0.3363 & 0.5787 & -0.5904 & 0.7345 & -0.1031 & -0.2128 & -0.2902 & 0.0018 \\
\hline 2006 & 1.2848 & 1.5004 & 0.2646 & 0.7064 & -0.6470 & 1.5811 & 1.0654 & 0.4049 & 0.1500 & -1.1686 \\
\hline 2007 & 1.4657 & 1.5724 & 0.2312 & 0.9227 & -0.3639 & 2.1455 & 1.6243 & 0.7578 & 0.0120 & -1.7628 \\
\hline 2008 & 1.7115 & 1.6030 & 0.2049 & 2.9167 & -0.0100 & 0.3112 & -0.4079 & -0.0363 & -0.3567 & -0.4675 \\
\hline 2009 & 1.8652 & 1.6310 & 0.2038 & 1.8293 & -0.8735 & 0.7345 & -0.0523 & -0.3011 & 1.1370 & -0.5079 \\
\hline 2010 & 1.9443 & 1.6814 & 0.1226 & 2.0734 & -0.2931 & 0.4523 & 1.1162 & 0.9343 & 0.8867 & -0.2603 \\
\hline 2011 & 2.2106 & 1.7784 & 0.0832 & 2.3298 & -0.1232 & 0.3112 & -0.8652 & 0.1401 & 0.0355 & 0.0485 \\
\hline
\end{tabular}




\subsection{Influence of Urbanization on Climate Change}

We use SPSS software to analyze the correlation coefficients between each urbanization index and meteorological elements in Nanjing, the correlation coefficients between each urbanization index and meteorological elements such as shown in Table 1.

\section{Table 1. The Correlation Coefficients between each Urbanization Index and Meteorological Elements}

\begin{tabular}{l|lllll}
\hline & $\mathrm{Y}_{1}$ & $\mathrm{Y}_{2}$ & $\mathrm{Y}_{3}$ & $\mathrm{Y}_{4}$ & $\mathrm{Y}_{5}$ \\
\hline $\mathrm{X}_{1}$ & $0.551^{* *}$ & 0.241 & 0.258 & 0.177 & -0.224 \\
$\mathrm{X}_{2}$ & $0.623^{* *}$ & 0.322 & 0.272 & 0.181 & -0.189 \\
$\mathrm{X}_{3}$ & $0.563^{* *}$ & 0.252 & 0.261 & 0.176 & -0.229 \\
$\mathrm{X}_{4}$ & $0.565^{* *}$ & 0.253 & 0.262 & 0.173 & -0.230 \\
$\mathrm{X}_{5}$ & $0.534^{* *}$ & 0.227 & 0.254 & 0.176 & -0.220 \\
$\mathrm{X}_{6}$ & $0.576^{* *}$ & 0.263 & 0.269 & 0.177 & 0.222 \\
$\mathrm{X}_{7}$ & $0.708^{* *}$ & $0.407^{*}$ & 0.269 & 0.250 & -0.251 \\
$\mathrm{X}_{8}$ & $0.661^{* *}$ & 0.327 & 0.301 & 0.215 & -0.288 \\
$\mathrm{X}_{9}$ & $-0.546^{* *}$ & -0.203 & -0.305 & -0.156 & 0.309 \\
$\mathrm{X}_{10}$ & $0.683^{* *}$ & $0.354^{*}$ & $0.435^{*}$ & 0.177 & -0.244 \\
$\mathrm{X}_{11}$ & $0.641^{* *}$ & 0.308 & $0.352^{*}$ & 0.184 & -0.263 \\
$\mathrm{X}_{12}$ & $0.651^{* *}$ & 0.347 & 0.425 & 0.198 & -0.270 \\
$\mathrm{X}_{13}$ & $0.557^{* *}$ & $0.364^{*}$ & 0.130 & 0.035 & -0.136 \\
$\mathrm{X}_{14}$ & $0.543^{* *}$ & 0.244 & 0.226 & 0.159 & -0.227 \\
$\mathrm{X}_{15}$ & -0.297 & -0.001 & -0.069 & -0.153 & 0.218 \\
\hline
\end{tabular}

**: significant level of 0.01 ; * significant level of 0.05 .

From Table 1 we found that the total population $\left(\mathrm{X}_{7}\right)$ is the index which affects the annual average temperature greatest, and the urban consumer price index $\left(X_{15}\right)$ is the weakest one, according to the absolute value of the correlation coefficient, influence the level of the order froruarirgest to smallest is as follows: $\mathrm{X}_{7}>\mathrm{X}_{1}>\mathrm{X}_{8}>\mathrm{X}_{2}>\mathrm{X}_{1}>\mathrm{X}_{2}>$ $X_{6}>X_{4}>X_{3}>X_{13}>X_{1}>X_{9}>X_{14}>X_{5}>X_{15}$, the agricultural population $\left(X_{9}\right)$ and the urban consumer price index $\left(\mathrm{X}_{15}\right)$ were found to be negatively correlated with the annual mean temperature $\left(\mathrm{Y}_{1}\right)$, and the correlation coefficient pass through 0.01 significant test, except the urban consumer price index $\left(\mathrm{X}_{15}\right)$. There is a certain effect on urban temperature from the population growth, the same regional change in land surface also had very important influence on urban temperature.

As the same to annual average temperature, the total population $\left(\mathrm{X}_{7}\right)$ is the index which affects the extreme minimum temperature greatest, and the urban consumer price index $\left(\mathrm{X}_{15}\right)$ is the weakest one, according to the absolute value of the correlation coefficient, influence the level of the order from largest to smallest is as follows: $X_{7}>X_{13}>X_{10}>$ $X_{12}>X_{8}>X_{2}>X_{11}>X_{6}>X_{4} \quad X_{3}>X_{14}>X_{1}>X_{5}>X_{9}>X_{15}$, only the correlation of the total population $\left(X_{7}\right)$, road length $\left(X_{10}\right)$, green coverage area $\left(X_{12}\right)$, land area $\left(X_{13}\right)$ and extreme minimum temperature $\left(\mathrm{Y}_{2}\right)$ pass through 0.05 significant test, but its correlation coefficient was not large, which explain the effect of urbanization on extreme minimum temperature is not significant.

The extreme maximum temperature is most affected by the road length $\left(\mathrm{X}_{10}\right)$, followed 
by green coverage area $\left(\mathrm{X}_{12}\right)$, the correlation coefficients were 0.435 and 0.425 , both pass through the 0.05 significant test, which explain that it is significant for the influence of the regional change in land surface due to urbanization on extreme maximum temperature.

The effect of urbanization on precipitation and sunlight hours is not obvious, the effects of single urbanization indicator on them are not very strong, the correlation coefficient is about 0.2 to 0.3 .

\section{Conclusions}

In the context of climate warming, urbanization affects local climate change, which causes a series of urban environmental quality problems. With the analysis in this article, we found that the warming trend in Nanjing is very weak, the mainly temperature change is a rising temperature in winter, while it was not obvious in summer, reduce the heat wave phenomenon, the average year temperature has increased slightly; over the years, precipitation increased by $17.43 \mathrm{~mm}$ every 10 years, but it was volatile during different periods; With the trend continues, the sunlight hours was decreasing by $66.28 \mathrm{~h}$ every 10 years, which reflects the effect of city dark island, and this may be related inseparable to fog haze caused by environmental pollution in the course of urbanization. Also through the analysis of the relationship between urbanization and clmate factors, we found that the total population, agricultural population and urban green area are close to annual average temperature, and it is significant; and the effect of urbanization on the extreme minimum temperature in Nanjing is not very significant, but affects extreme maximum temperature obviously, the correlation coefficients of the rod length and green coverage area were 0.435 and 0.425 , both pass througn the 0.05 significant test, which explain that it is significant for the influence of the regional change in land surface due to urbanization on extreme maximum temperature. At last we found that years of reform and opening-up become the theory cut-off point of the trend on climate change and the effect of urbanization on climate change before and after the cut-off point, climate change and urbanization effect on climate change have signiticant differences, the reasons and related mechanism still need further analysis and discussion.

\section{Acknowledgments}

This work is Supported by the Dynamic mechanism of desertification in response to climate change in Qinghai Lake (41375160), evaluation of solar energy resources and the related studies of efficjency and effectiveness of photovoltaic (1213013) and effect of urbanization on climate change-a case study of Yangtze River delta (2010JDXM027). Prof. Wenzheng Yuis the corresponding author.

\section{References}

[1] J. Menglin and J. Marshall, "Inclusion of urban landscape in a climate model", Bulletin of American Meteorological Society, vol. 86, (2005), pp. 681-689.

United Nations Human Settlements Programme, Cities and climate change. Global report on human

[3] X. Xiazhen, Z. Youfei, Y. Jifu and W. Rongjun, "Characteristics of high temperature and heat wave in Nanjing City and their impacts on human health", Journal of animal ecology, vol. 30, no. 12, pp. 2815-2820. 


\section{Authors}

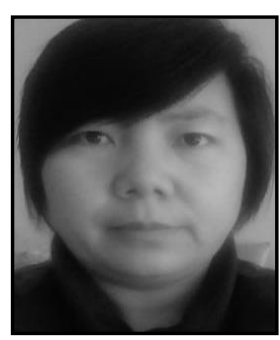

Qi Yingxiang, female, master of China University of Political science and Law, associate professor, mainly engaged in the research about policy of resources and environment.

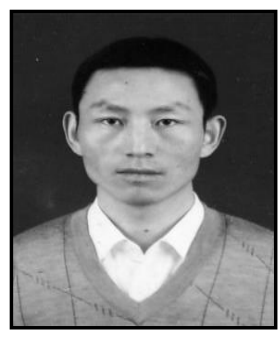

Yu Wenzheng, male, Ph.D. and professor, mainly engaged in climate change, the evolution of regional environment and the sustainable utilization of resources (including land and climate resources). E-mail: ywzheng519@126.com

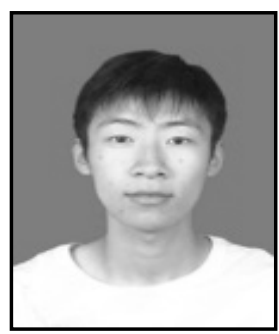

Shao Li, male, master candidate, mainly engaged in effect of urbanization on climate change.E-mail»shaoli20081317@163.com

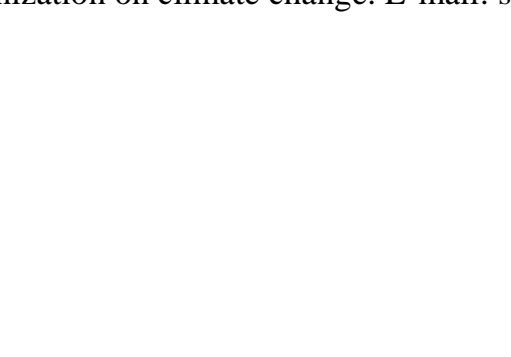

Chen Tianliang, male, master candidate, mainly engaged in effect of

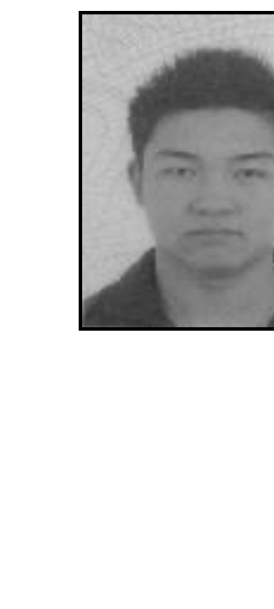

urbanization-on chmate change. E-mail: g1z217@163.com 